\title{
The Assessment of Alumina Production Waste Impact on Natural Water
}

\author{
Vladimir Sergeevich Kuznetsov ${ }^{1}$, Igor Konstantinovich Suprun ${ }^{1 *}$ \\ 1 Department of Geoecology, Saint-Petersburg Mining University, Vasilievskiy Island 21st Line 2, 199106, Saint- \\ Petersburg, Russian Federation \\ * Corresponding author's e-mail: igor_suprun@mail.ru
}

\begin{abstract}
The paper is dedicated to the issue of assessment of alumina (red mud) production waste on natural water. The growth of the number of aluminium-producing facilitites leads to the expansion of exclusion areas to store the production waste - sludge dumps. A considerable part of research on red mud utilisation is focused on its use in the iron-and-steel industry. Furthermore, the technologies of red mud usage in the construction industry gain substantial significance for land reclamation, isolation of polluted industrial and agricultural lands as well as the effluent and industrial emissions treatment.
\end{abstract}

Keywords: alumina, red mud, utilisation, sludge dump.

\section{INTRODUCTION}

Currently, an increasing attention is paid to the creation of waste free technologies, which includes red mud processing [Alekseev, 2016]. The creation of such sludge technologies is based on the usage of all useful mud components. Concurrently, special attention is given to the enhancement of efficiency in rare earth metal extraction, especially scandium [Yushina et al., 2014]. Besides scandium, red mud contains yet another valuable element, i.e. yttrium. Extraction of this element also carries a significant meaning [Pasechnik et al., 2013]. As for the scandium content in its composition, red mud is similar to scandium deficient materials. However, currently in Russia there are no facilities capable of processing deficient materials.

In view of the increasing number of production facilities and a huge amount of accumulated waste, the necessity of transitioning from sludge storage to its processing seems unquestionable.

The global alumina industry mainly processes high quality bauxites by means of the hydrochemical Bayer process [Romentsa, 2005]. This method is the most cost-efficient. However, low quality bauxites are processed by means of a more expensive, but at the same time a more universal approach - agglomeration [Technology of alumina production, 2017]. The main alumina production is incapable of causing significant harm to the environment. The exception to this statement is sludge dumps for alumina (red mud) production storage.

Red mud is a mixture of solid and liquid bodies. The liquid body of red mud is aggressive, as it contains $4-15 \mathrm{~g} / \mathrm{dm}^{3}$ natric caustic soda and $\mathrm{pH}$ up to 12.9 . The solid body of red mud is not toxic and consists of a high number of iron, aluminium, calcium, silicon, titanium oxides as well as the oxides of other metals.

Sludge dumps occupy hundreds of hectares. Their height reaches 30-35 metres for bauxite red mud and 100 metres for nephelinic red mud. This work provides an assessment of red mud waste negative impact on natural water.

Sludge dumps are the source of the negative impact on the environment. The greatest negative influence comes from sludge dumps which constitute the sources of active and potential leakages of rich alkali slime water into surface and underground natural water. The impact of 
the sludge dump located in the Leningrad Region of the Russian Federation, next to the production unit performing alumina recovery will now be examined. While building the sludge dumps, the production unit did not conduct any specific screening of the foundation. As clay loam mantles are not deposited along the whole space of the foundation, vertical filtration of slime water into sandy ground and further, into ground water basins, seems possible. Pollution of underground water under and around the sludge dump was registered at the production unit [PND F 12.4.2.1-99].

\section{MATERIALS AND METHODS}

In order to assess the impact of sludge dump on natural water in the region, waste sample collection was conducted [PND F 12.4.2.1-99]. The collected samples were examined by means of qualitative, quantitative and granulometric analyses. The quantitative and qualitative analyses were conducted using the approach of X-ray fluorescence spectrometry while granulometric analysis was performed using the sieve approach [Hygienic standards 12536-79]. X-ray fluorescence analysis allowed to detect a full blend composition of examined production waste.
The granulometric waste composition was determined using the sieve approach. In order to perform the analysis, a selection of 7 sieves with the mesh diameter of $10 ; 5 ; 2 ; 1 ; 0.5 ; 0.25 ; 0.1$ $\mathrm{mm}$ was used [Hygienic standards 12536-79]. The the data concerning the level of pollution of surface watercourses, water samples [Hygienic standards 31861-2012] from water objects (Figure 1) were collected in the region of waste disposal site location.

One of the ways by means of which contaminants infiltrate into natural water is their seepage through the "body" of the sludge dump. While going through the waste mass, atmosphere precipitations react with them on a chemical level, which results in dissolution (desalination) of waste components and removal of contaminants. The underground water becomes polluted as a result of seepage. Furthermore, underground water can be polluted as a result of direct waste contact in the case of its level elevation to the level of sludge dump bottom.

\section{RESULTS AND DISCUSSIONS}

The results of red mud sample analysis are presented in Tables 1 and 2 [Shirkin L.A., 2009]. In order to establish the nature of interaction be-

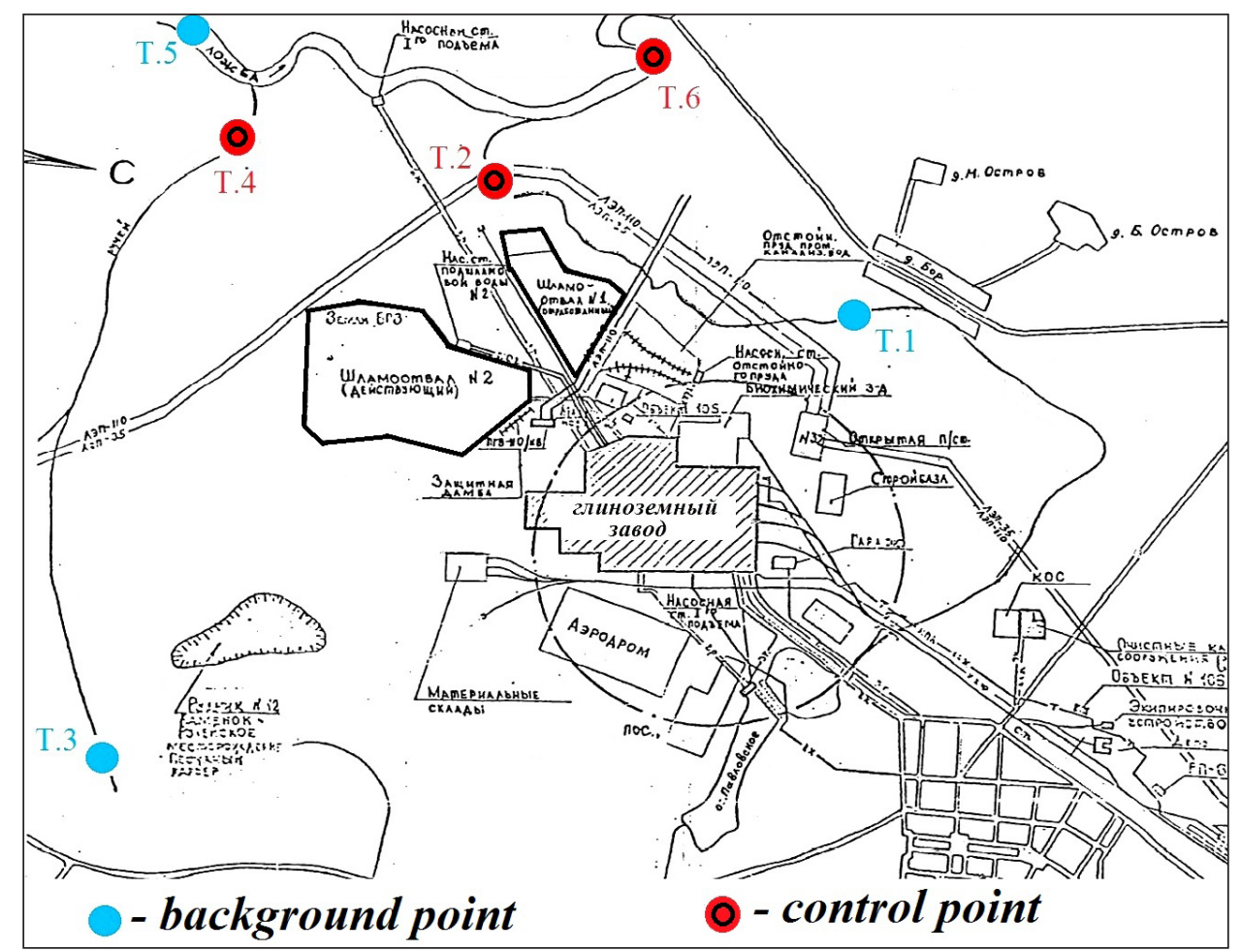

Figure 1. Research objects in the region of waste disposal site location 
tween red mud and water, chemical analysis of water extracts was performed.

In order to simulate different conditions of desalination, the prepared water extracts contained different mediums: sour $-\mathrm{pH} 4$ (simulation of atmosphere precipitations), alkaline $-\mathrm{pH}$ 8 (simulation of underground water) and the interaction of waste with distilled water $(\mathrm{pH} 5.8)$ was also examined.

The quantitative sample analysis for the content of cathions washed out into solution from waste was performed on ICPE 9000 atomic emission spectrometer with inductively coupled plasma and Shimadzu AA-7000atomic absorption spectrophotometer [Ivlev, 2014; Beizel, 2008].

As the chief components contained in waste are iron, aluminium and calcium with traces of potassium, magnesium, sodium, manganese and chrome, the obtained water extracts were ana-

Table 1. The results of semi-quantitative X-ray fluorescent analysis of red mud samples

\begin{tabular}{|c|c|c|c|}
\hline $\begin{array}{c}\text { Element } \\
\text { oxide }\end{array}$ & $\begin{array}{c}\text { Concentration, } \\
\text { wt } \%\end{array}$ & $\begin{array}{c}\text { Element } \\
\text { oxide }\end{array}$ & $\begin{array}{c}\text { Concentration, } \\
\text { wt\% }\end{array}$ \\
\hline $\mathrm{CaO}$ & 33.42 & $\mathrm{Cr}_{2} \mathrm{O}_{3}$ & 0.27 \\
\hline $\mathrm{Fe}_{2} \mathrm{O}_{3}$ & 26.81 & $\mathrm{P}_{2} \mathrm{O}_{5}$ & 0.25 \\
\hline $\mathrm{SiO}_{2}$ & 18.58 & $\mathrm{SO}_{3}$ & 0.25 \\
\hline $\mathrm{Al}_{2} \mathrm{O}_{3}$ & 12.33 & $\mathrm{ZrO}_{2}$ & 0.14 \\
\hline $\mathrm{TiO}_{2}$ & 3.82 & $\mathrm{SrO}$ & 0.09 \\
\hline $\mathrm{Na}_{2} \mathrm{O}$ & 1.55 & $\mathrm{NiO}$ & 0.05 \\
\hline $\mathrm{MgO}$ & 1.18 & $\mathrm{ZnO}$ & 0.03 \\
\hline $\mathrm{K} \mathrm{O}$ & 0.71 & $\mathrm{CuO}$ & 0.02 \\
\hline $\mathrm{MnO}$ & 0.47 & & \\
\hline
\end{tabular}

lysed for the presence of these components. Tables 3 and 4 present the results of analysis (note: samples no. 1 and 2 - sour medium, no. 3 and 4 - distilled water, no 5 and 6 - alkaline medium).

On the basis of the data obtained, one can state that factor $\mathrm{pH}$ indicators impact the number of washed out elements only in relation to calcium, iron, sodium and manganese. In relation to other determined components, concentration variations in different conditions are minimal.

Currently, the quantity of waste contained in the waste dump is estimated as 30 million tonnes. Taking into consideration the material migration from the waste dump, an estimated number of contaminating components, which over the course of time can infiltrate into nearby water objects as well as underground water is presented in Table 5.

On the basis of the data obtained, one can conclude that during the seepage of atmosphere precipitations through the body of sludge dump, a significant number of contaminants can infiltrate into the environment and there is a risk of the occurrence of a hydrochemical halo of contamination. The next stage of the work is the assessment of the existing state of water objects located by the sludge dump.

On the basis of the previously obtained results, a list of determinable components, i.e. iron, aluminium and manganese, was comprised. The results of water sample analysis are presented in Table 6 [Stoykova, 2010]. The data obtained indicates that in the location of the production unit, sludge dump a process of precipitations' seep-

Table 2. The results of granulometric analysis

\begin{tabular}{|c|c|c|c|c|c|c|c|c|}
\hline Grading fraction, $\mathrm{mm}$ & $>10$ & $10-5$ & $5-2$ & $2-1$ & $1-0.5$ & $0.5-0.25$ & $0.25-0.1$ & $<0.1$ \\
\hline Concentration, wt $\%$ & 6.67 & 46.59 & 37.23 & 6.73 & 1.11 & 0.17 & 0.53 & 0.60 \\
\hline
\end{tabular}

Table 3. The results of analysis conducted by means of atomic emission spectrometry

\begin{tabular}{|c|c|c|c|c|c|c|c|c|c|}
\hline Component & 1 & 2 & $\mathrm{C}_{1,2}, \mathrm{mg} / \mathrm{dm}^{3}$ & 3 & 4 & $\mathrm{C}_{3,4}, \mathrm{mg} / \mathrm{dm}^{3}$ & 5 & 6 & $\mathrm{C}_{5,6}, \mathrm{mg}^{\prime} \mathrm{dm}^{3}$ \\
\hline $\mathrm{Al}$ & 1.0 & 1.15 & 1.075 & 1.06 & 1.06 & 1.06 & 1.13 & 1.05 & 1.09 \\
\hline $\mathrm{Ca}$ & 6.54 & 7.1 & 6.82 & 6.8 & 7.36 & 7.08 & 8.43 & 8.32 & 8.375 \\
\hline $\mathrm{Fe}$ & 0.42 & 0.674 & 0.547 & 0.664 & 0.631 & 0.6475 & 0.818 & 0.721 & 0.7695 \\
\hline $\mathrm{K}$ & 2.29 & 2.82 & 2.555 & 3.62 & 3.35 & 3.485 & 4.20 & 4.34 & 4.27 \\
\hline $\mathrm{Mg}$ & 1.07 & 1.17 & 1.12 & 1.2 & 1.34 & 1.27 & 1.54 & 1.49 & 1.515 \\
\hline $\mathrm{Na}$ & 13.8 & 15.5 & 14.65 & 15.6 & 14.10 & 14.85 & 20.10 & 22.8 & 21.45 \\
\hline
\end{tabular}

Table 4. The results of analysis conducted by means of atomic absorption spectrophotometry.

\begin{tabular}{|c|c|c|c|c|c|c|c|c|c|}
\hline Component & 1 & 2 & $\mathrm{C}_{1,2}, \mathrm{mg} / \mathrm{dm}^{3}$ & 3 & 4 & $\mathrm{C}_{3,4}, \mathrm{mg} / \mathrm{dm}^{3}$ & 5 & 6 & $\mathrm{C}_{5,6}, \mathrm{mg}^{\prime} \mathrm{dm}^{3}$ \\
\hline $\mathrm{Mn}$ & 34.26 & 33.08 & 33.67 & 37.38 & 33.51 & 35.44 & 43.63 & 37.89 & 40.76 \\
\hline $\mathrm{Cr}$ & 15.23 & 4.57 & 9.91 & 10.68 & 5.51 & 8.091 & 7.19 & 8.96 & 8.08 \\
\hline
\end{tabular}


Table 5. The number of contaminants exposed to washing out

\begin{tabular}{|c|c|c|c|}
\hline Component & Weight, ton & Component & Weight, ton \\
\hline $\mathrm{Al}$ & 253.8 & $\mathrm{Mg}$ & 509 \\
\hline $\mathrm{Ca}$ & 2865 & $\mathrm{Na}$ & 7260 \\
\hline $\mathrm{Fe}$ & 166.1 & $\mathrm{Mn}$ & 9.84 \\
\hline $\mathrm{K}$ & 1347 & $\mathrm{Cr}$ & 2.34 \\
\hline
\end{tabular}

Table 6. The results of water sample analysis

\begin{tabular}{|c|c|c|c|c|c|c|c|}
\hline \multirow{2}{*}{ Component } & \multicolumn{5}{|c|}{ Concentration of pollutant in point number, $\mathrm{mg} / \mathrm{dm}^{3}$} & Maximum admissible \\
\cline { 2 - 7 } & 1 & 2 & 3 & 4 & 5 & 6 & ${\text { concentration, } \mathrm{mg} / \mathrm{dm}^{3}}^{3}$ \\
\hline $\mathrm{Fe}$ & 0.450 & 0.520 & 0.220 & 0.370 & 0.570 & 0.630 & 0.10 \\
\hline $\mathrm{Al}$ & 0.028 & 0.030 & 0.011 & 0.017 & 0.048 & 0.053 & 0.04 \\
\hline $\mathrm{Mn}$ & 0.026 & 0.033 & 0.005 & 0.008 & 0.039 & 0.046 & 0.01 \\
\hline
\end{tabular}

age and washing out of contaminants into underground water takes place, which contributes to the contamination of nearby water courses.

\section{CONCLUSIONS}

On the basis of the results of the research conducted, one can state that calcium, iron, silicon, aluminium, titanium, sodium, magnesium, potassium, manganese and chrome oxides prevail in the verified sludge composition of alumina production. Taking into account the granulometric composition, one can draw conclusions concerning the prevalence of chisley and gravelly soil.

Watertight screen was not provided in the sludge dump arrangement. Furthermore, the natural base of the sludge dump is laid with clay loam mantles which do not have a sufficient degree of water resistance, nor are they located across the whole area of the base, in the places alternating with sand clay. On this account, seepage of atmosphere precipitations through the sludge mass takes place, which leads to waste components desalination and their migration to underground water. Underground water discharges to nearby water courses, which encourages the expansion of negative impact area of the sludge dump.

As a result of examination of water samples collected from these water courses, one can state that during the seepage of atmosphere precipitations, such components as iron and manganese infiltrate into surface water objects. In natural water of the area where alumina production is located, an increased concentration of aluminium is being noted; however, the sludge dump is not the source of this contamination as an increase in concentration was not detected in the investigated effluents. Furthermore, aluminium has a low migration capacity, which yet again proves that the sludge dump did not contribute to the contamination of the water course with aluminium.

Having considered and analysed the existing position in the area of red mud accumulation and processing, one can state the following: red mud is a mineral stock of industry-related origin, which can be used in various types of business operation: lumping of ores and concentrates; comprehensive mineral processing to receive cast iron, alumina and concrete, mixed cement, hydraulic additives into Portland cement; usage as fillers for bituminous concretes and road surfaces; production of glass, baked and silex bricks, slag glass materials and backfills, sewage pipes; mixing colours; filling mixtures and foundry moulding compounds; production of sorbents, coagulants and catalysts; release of fertilizers.

Currently, a mass consumption of red mud can be provided by the iron-and-steel industry and the production of construction materials.

\section{REFERENCES}

1. Alekseev A.I. 2016. Scientific principles of processing of aluminum containing waste. Zapiski Gornogo Instituta, Vol. 219, 428-434. DOI 10.18454 / PMI.2016.3.428.

2. Beizel N.F. 2008. Atomic Absorption Spectrometry. Novosibirsk State University. Novosibirsk, pp. 72.

3. Hygienic standards 12536-79 "Methods for laboratory determination of granulometric (grain) and micro aggregate composition". 
4. Hygienic standards 31861-2012 "Water. General requirements for sampling".

5. Ivlev S.I., Sobolev V.I. 2014. Atomic-emission analysis: methodological instructions for performing laboratory work. Tomsk Polytechnic University, Tomsk, pp. 26.

6. Pasechnik L.A., Yatsenko A.S., Yatsenko S.P., Skryabneva L.M. 2013. Selective extraction of yttrium from slimes of alumina production. Nonferrous Metals, No. 12, 39-43.

7. PND F 12.4.2.1-99 "Waste of mineral origin. Recommendations for the selection and preparation of samples. General provisions".
8. Romentsa V.A. 2005. The Romelt process. MISiS, Publishing House "Ore and Metals", pp. 400.

9. Shirkin L.A. 2009. X-ray fluorescence analysis of environmental objects. Vladimirskiy State Univ., pp. 65.

10. Stoykova E.E., Medyantseva E.P., Evtyugin G.A. 2010. Hydrochemical analysis. Kazan (Privolzhsky) Federal University, pp. 49.

11. Technology of alumina production. URL: http:// media.ls.urfu.ru/201/584/1331/ (31.10.2017)

12. Yushina T.I., Petrov I.M., Grishaev S.I., Cherny S.A. 2014. Analysis of modern technologies of processing and enrichment of rare-earth raw materials. Tsvetnaya Metallurgiya, No. 5, 61-63. 